\author{
Waldemar Studziński, Alicja Gackowska \\ UTP University of Science and Technology, Faculty of Chemical Technology and Engineering \\ Seminaryjna 3 Str., 85-326 Bydgoszcz, Poland, Waldemar.Studzinski@utp.edu.pl
}

\title{
REMOVAL OF 2-PHENYLBENZIMIDAZOLE-5-SULFONIC ACID USING HETEROGENEOUS PHOTOCATALYSIS
}

\begin{abstract}
UV filters are classified as environmental pollutants (emerging pollutants). One of the most frequently detected UV filters in real samples is 2-phenylbenzimidazole-5-sulfonic acid (PBSA). It has been shown that conventional technologies applied in sewage treatment plants are not adapted for complete removal of sunscreen agents. Therefore, there is a trend to undertake activities leading to improvement of water quality by enhancing treatment methods. This is important due to the fact that in an aqueous environment, in the presence of UV radiation or sunlight irradation, PBSA generates reactive oxygen species that can damage the DNA of living organisms.
\end{abstract}

The aim of study was to investigate an effect of $\mathrm{pH}$ and $\mathrm{TiO}_{2}$ on PBSA stability in the presence of UV radiation. It was found that the rate of PBSA degradation depends on the catalyst dose and $\mathrm{pH}$ of solution. The photocatalysis reaction was carried out in a Heraeus laboratory exposure set equipped with a $150 \mathrm{~W}$ mediumpressure mercury lamp. The course of PBSA degradation process as a function of time was monitored using UV/VIS spectrophotometer and liquid chromatograph equipped with UV-Vis detector.

\section{Key words}

PBSA, UV filter, emerging pollutants, photodegradation, $\mathrm{TiO}_{2}$

\section{Introduction}

Organic environment micro-pollutants (emerging pollutants) are a global challenge related to water quality. These substances have been identified in the environment but they are not included in routine environmental monitoring programs. Their fate in the environment and ecotoxicological impact on living organisms are unknown [1]. The micro-pollutants of the environment include, among others, pharmaceutical products and personal care products which are used every day and at the final stage they get into surface water or sewage [2]. One of the components of personal care products are UV filters. These compounds are mainly used in sun creams and other cosmetic preparations (lipsticks, make-up agents, lotions, shampoos) protecting people against the harmful effects of UV radiation [3].

It was revealed that UV filters get into environment together with sewage as a result of washing off from the skin or clothes. These compounds were detected in surface waters, recreational waters as well as in sewage and sediments even at levels of $\mathrm{mg} \cdot \mathrm{L}^{-1}$ or $\mathrm{mg} \cdot \mathrm{kg}^{-1}[4,5]$. The maximum levels of UV filters have been determined in summer, as most cosmetics containing sunscreens are used during this period $[3,5,6,7]$. In water matrices, the most frequently are detected derivatives of benzophenone, cinnamic acid and benzimiadazole [8].

2-Phenylbenzimidazole-5-sulfonic acid (PBSA), as one kind of sunscreen, is widely used in sunscreen formulations and cosmetics because of its strong absorption in the UVB region [9]. PBSA is characterized by high polarity. It has been identified in surface waters at the level from 109 to $2679 \mathrm{ng} \cdot \mathrm{L}^{-1}$ [10]. Studies have shown that PBSA under the influence of sunlight irradiation can cause DNA damage, because it is a source of reactive oxygen species (ROS) [11].

Some studies have shown that UV filters are stable against biotic degradation. In addition, toxicological studies suggest that some organic filters have estrogenic and antithyroid properties and can be bioaccomulated [12, 13]. Hence, UV filters are a potential danger to human health and the ecosystem. Moreover, products of UV filter conversions under the influence of environmental agents can be more toxic than the initial compounds. For this reason, they are considered as priority pollutants, which should be subject to special monitoring [14]. Another important aspect is that UV filters which penetrate wastewater are not effectively removed. Conventional wastewater treatment methods are not suitable for disposal of organic micro-pollutants. Liu et al. 
observed on the municipal wastewater treatment plant which consisted of primary sedimentation and secondary activation of the processed sediments, the efficiency of elimination of 6 UV filters at the level of 5$82 \%$ [15]. In turn, application of adsorption on the sediment of lipophilic filters (log Kow> 4.0) such as avobenzone, homosalat, 4-methylbenzylidenecamphor (4-MBC), octyl-dimethyl-p-minobenzoic acid (ODPABA), octocrylene and 2-ethylhexyl 4-methoxycinnamate (EHMC) eliminates them from wastewater at the level of $30-70 \%$ [15-17]. Coagulation process and flocculation were also ineffective methods for elimination of 2,4dihydroxybenzophenone (BP-1) and 2-hydroxy-4-methoxy benzophenone-5-sulfonic acid (BP-4) [17, 18]. Low effectiveness of degradation UV filters was achieved in the process with the use of natural light. The tested filters contain chromophore groups, whose photoactive states are very stable and can change energy absorbed from light into thermal energy without changing their chemical structure [19]. However, in the process of water disinfection, benzophenone-3 (BP-3), 4-MBC, EHMC and octocrylene were eliminated by $17-25 \%$. In addition, this process produces halogenated by-products which can be toxic $[20,21]$. Therefore, the attempts are undertaken to find more effective methods for inactivation or elimination of sunscreens from wastewater [22].

Advanced oxidation processes (AOP) have been successfully used to remove various organic pollutants such as pesticides and herbicides from water environment [23-25]. Due to the simplicity and effectiveness, one of the most often applied AOPs is UV/ $\mathrm{H}_{2} \mathrm{O}_{2}$ system which degrades organic compounds as a result of selective attack of $\mathrm{OH} \bullet$ radicals [26]. An effective solution is also homogeneous photocatalysis with Fenton reagents. $\mathrm{SO}_{4} \bullet \bullet$, which is characterized by strong oxidizing properties at various $\mathrm{pH}$ values of solutions and is recommended for the degradation of organic compounds of considerable durability. Another method is heterogeneous photocatalysis using nanoparticles of $\mathrm{TiO}_{2}$ catalyst $[27,28]$. $\mathrm{TiO}_{2} \mathrm{P} 25$ is a photoactive, highly chemically stable, cheap and non-toxic catalyst [28].

This paper presents results of studies on the heterogeneous photocatalysis of organic PBSA UV filter under various experimental conditions in the presence of UV irradiation.

\section{Materials and methods}

Materials

All chemicals were purchased from commercial suppliers and used without purification. 2 phenylbenzimidazole 5 sulfonic acid (PBSA, CAS: 5466-77-3) was obtained from Sigma-Aldrich (USA). Reference standards ( $\mathrm{pH}$ 2- $\mathrm{pH}$ 14) were obtained from POCh (Poland). $\mathrm{TiO}_{2} \mathrm{P} 25$ (Surface Area $50 \mathrm{~m}^{2} \cdot \mathrm{g}^{-1}$ ) TiO $\mathrm{T}_{2}$ PC105 (Surface Area $90 \mathrm{~m}^{2} \cdot \mathrm{g}^{-1}$ ), $\mathrm{TiO}_{2}$ PC500 (Surface Area $350 \mathrm{~m}^{2} \cdot \mathrm{g}^{-1}$ ), were supplied by CristalACTiV ${ }^{\mathrm{TM}}$.

\section{Reaction conditions: Photocatalytic experiment}

The photocatalytic experiments were conducted on a laboratory scale using a Heraeus reactor equipped with a medium-pressure mercury lamp with a range of 200-600 $\mathrm{nm}$. The mercury lamp was cooled with water to temperature of $20^{\circ} \mathrm{C}$. Water solutions of PBSA at a concentration of $10 \mathrm{mg} \cdot \mathrm{L}^{-1}$ were introduced into laboratory reactor. Then, the specified doses of $\mathrm{TiO}_{2}$ catalyst were added. The system prepared in this way was subjected to UV irradiation. In order to ensure uniform distribution of the reactants, the solution was mixed using a magnetic stirrer (200rpm). Composition of the tested solutions is presented in Table 1. Effect of the specific surface area of catalyst on the photocatalysis rates was investigated using three types of titanium dioxide: $\mathrm{TiO}_{2}$ $\mathrm{P} 25, \mathrm{TiO}_{2}$ PC 105 and $\mathrm{TiO}_{2}$ PC 500, which were added in an amount of $20 \mathrm{mg}$. Effect of pH on the rate of photocatalysis was checked using $\mathrm{TiO}_{2} \mathrm{P} 25$. The $\mathrm{pH}$ value and proportions of catalyst in the individual systems is given in Table 1. The $\mathrm{pH}$ of solutions was adjusted with buffers. Photocatalyst doses were determined during preliminary tests. The time of catalyst contact with water PBSA solution before irradiation was set to 15 minutes in order to achieve a balance between adsorption and desorption. 
Table 1. The reaction conditions and substrate proportions used in this study

\begin{tabular}{|c|c|c|c|c|}
\hline System number & PBSA $\left[\mathrm{mg} \cdot \mathrm{L}^{-1}\right]$ & $\mathrm{TiO}_{2}$ P25 $\left[\mathrm{mg} \cdot \mathrm{L}^{-1}\right]$ & $\mathrm{pH}$ & UV [W] \\
\hline 1 & \multirow{9}{*}{10} & - & 7 & \multirow{9}{*}{150} \\
\hline 2 & & 1 & 7 & \\
\hline 3 & & 5 & 7 & \\
\hline 4 & & 10 & 7 & \\
\hline 5 & & 20 & 7 & \\
\hline 6 & & 40 & 7 & \\
\hline 7 & & 1 & 3 & \\
\hline 8 & & 1 & 5 & \\
\hline 9 & & 1 & 12 & \\
\hline
\end{tabular}

Source: Author's

\section{Analytical methods}

Sampling procedure

Samples for quantitative analysis were drawn every 5 minutes. $10 \mathrm{ml}$ of solution was sampled from each system studied. Separation of water mixture from catalyst was carried out using a filtration kit, which consisted of a $45 \mu \mathrm{m}$ PTFE filter. Change in PBSA concentration as a function of time was controlled by the spectrophotometric and chromatographic methods.

\section{Spectrophotometric analysis}

UV/Vis Academy Spectra View 2100 spectrophotometer was used for spectrophotometric analysis. Spectrophotometric analysis was carried out in the range of $200-400 \mathrm{~nm}$. The detection wavelength was 245 $\mathrm{nm}$ and $302 \mathrm{~nm}$ for PBSA.

\section{High performance liquid chromatography}

Chromatographic analysis was carried out using a high performance liquid chromatograph SHIMADZU, equipped with UV-Vis SPD-20AV SHIMADZU detector. Discovery ${ }^{\circledR}$ HS Supelco C18 column $(15 \mathrm{~cm} \times 4.6 \mathrm{~mm}, 5$ $\mu \mathrm{m})$ was used for separation. The mobile phase consisted of $1 \%$ acetic acid in water and $96 \%$ ethanol in a ratio of 80:20 (v:v). The flow rate was $1 \mathrm{ml} / \mathrm{min}$ with a $20 \mu \mathrm{l}$ injection volume. The detection wavelength was $245 \mathrm{~nm}$ and $302 \mathrm{~nm}$ for PBSA. HPLC analysis based on peak areas.

\section{Results}

Effect of UV radiation and $\mathrm{TiO}_{2}$ catalyst on PBSA degradation was controlled by two methods: spectrophotometric and chromatographic. In the first stage, both methods were verified in terms of linearity and repeatability. Limits of detection (LOD) and quantification (LOQ) were also determined.

Table 2. Linear range, calibration curves, relative, relative standard deviation (RSD) and LOQs and LODs

\begin{tabular}{|c|c|c|}
\hline Parameters & HPLC method & $\begin{array}{c}\text { Spectrophotometric } \\
\text { method }\end{array}$ \\
\hline Range $\left[\mathrm{mg} \cdot \mathrm{L}^{-1}\right]$ & $0.0003-10.0$ & $0.3-10.0$ \\
\hline $\mathrm{R}^{2}$ & 0.9997 & 0.9983 \\
\hline $\mathrm{RSD}[\%]$ & 3.2 & 2.0 \\
\hline $\mathrm{a}$ & 26280 & 0.0867 \\
\hline $\mathrm{b}$ & -3854.9 & 0.0273 \\
\hline $\mathrm{LOQ}$ & $0.3 \mu \mathrm{g} \cdot \mathrm{L}^{-1}$ & $0.3 \mathrm{mg} \cdot \mathrm{L}^{-1}$ \\
\hline $\mathrm{LOD}$ & $0.1 \mu \mathrm{g} \cdot \mathrm{L}^{-1}$ & $0.1 \mathrm{mg} \cdot \mathrm{L}^{-1}$ \\
\hline
\end{tabular}

Source: Author's

$y=a x+b$ 
Both methods are characterized by linearity and repeatability (Table 1.). For the spectrophotometric method, the linearity range was in the range of $0.3-10.0 \mathrm{mg} \bullet \mathrm{L}^{-1}$. The standard curve was determined based on solutions with concentrations of $0.3 ; 0.5 ; 1.0 ; 2.0 ; 5.0 ; 10.0 \mathrm{mg} \bullet{ }^{\mathrm{L}-1}$. For the HPLC method, the linearity range was in the range of $0.0003-10.0 \mathrm{mg} \cdot \mathrm{L}^{-1}$. The calibration curve consisted of 8 points with concentrations of 0.0003 ; $0.0001 ; 0.001 ; 0.01 ; 0.1 ; 1.0 ; 10.0 \mathrm{mg} \bullet \mathrm{L}-1$. Each point of the calibration curve was performed in a four-fold repeat for two methods. The LOD and LOQ were determined as described Voigtman et al.[29]. The LOD for the HPLC and spectrophotometric method was calculated based on the signal to noise ratio. The LOD value was three times the value of the noise. The limit of quantification was three times the limit of detection (LOQ = 3LOD). The HPLC UV-Vis method allows us to determine PBSA concentration at lower level than spectrophotometric method.

In the next stage, the effect of UV irradiation on stability of PBSA was checked. It was found that PBSA was degraded by $90 \%$ within an hour. The obtained results are consistent with those described by Abdelraheem et al. [11], who showed that in the water environment PBSA is capable of the photo-generating reactive oxygen species under UV irradiation. The nascent oxygen radicals are precursors of further PBSA conversions, which can result in formation of products with significantly higher toxicity than the substrate. Change of absorbance in time is presented in Fig. 1.

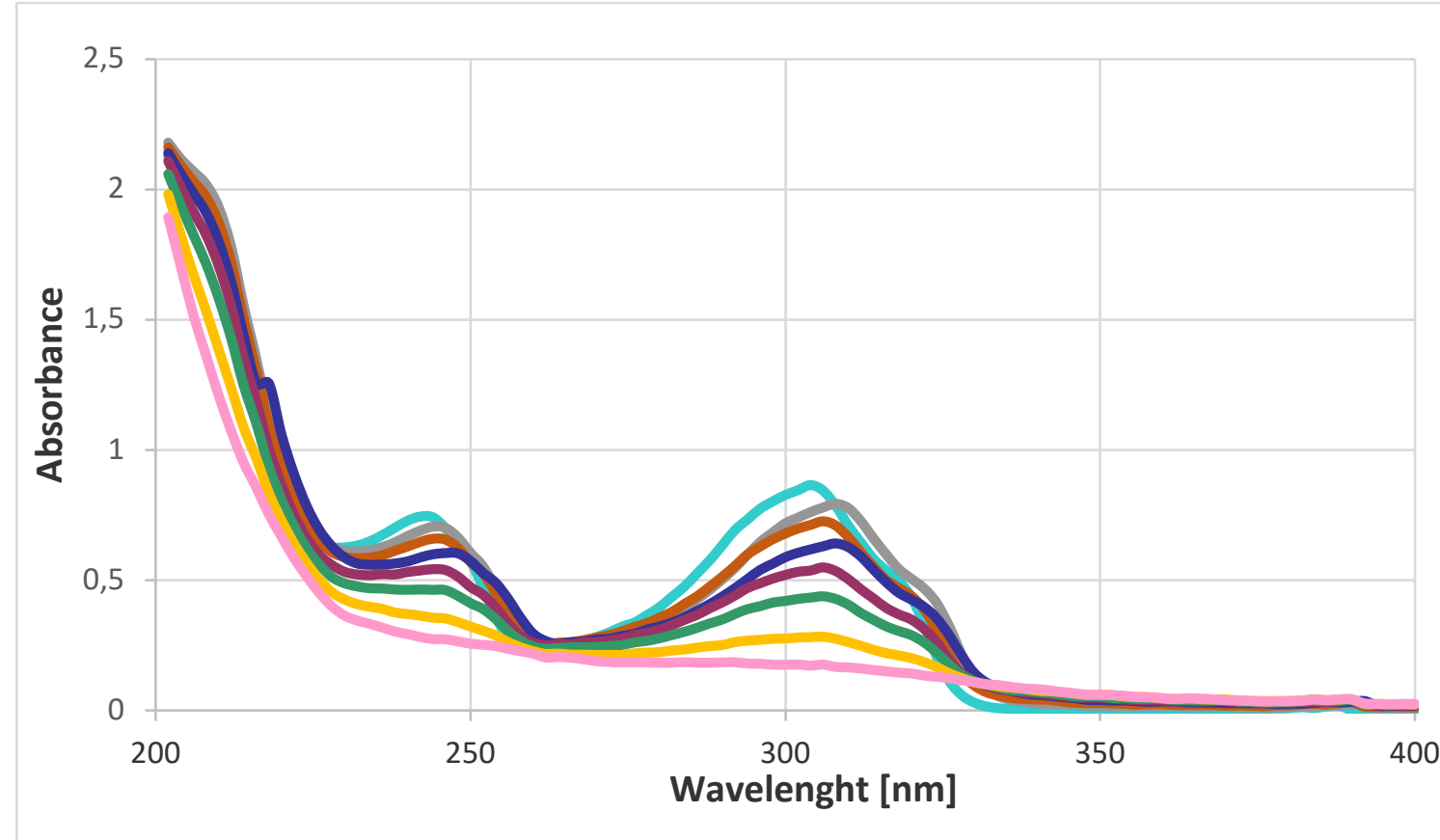

Fig. 1. Change in absorbance of PBSA under the influence of irradiation as a function of time: $-0 \mathrm{~min} ;-10 \mathrm{~min} ;-20$

$$
\begin{gathered}
\mathrm{min} ;-30 \mathrm{~min} ;-40 \mathrm{~min} ;-50 \mathrm{~min} ;-60 \mathrm{~min} ;-70 \mathrm{~min} \\
\text { Source: Author's }
\end{gathered}
$$

Another method used for degradation of organic contaminants is heterogeneous photolysis. It consists in simultaneous use of $\mathrm{TiO}_{2}$ and UV catalysts. Introduction additionally $\mathrm{TiO}_{2}$ to PBSA/UV system affected the rate of UV filter degradation. The tests were carried out using three $\mathrm{TiO}_{2}$ catalysts differing in surface area i.e. $\mathrm{TiO}_{2}$ $\mathrm{P} 25, \mathrm{TiO}_{2} \mathrm{PC} 105$ and $\mathrm{TiO}_{2} \mathrm{PC} 500$. The satisfactory results were obtained in the presence of each of the photocatalysts used (Fig. 2.). The highest loss in PBSA concentration was observed in the presence of $\mathrm{TiO}_{2} \mathrm{P}_{25}$, characterized by the smallest specific surface area. Therefore, $\mathrm{TiO}_{2} \mathrm{P} 25$ was used for further investigations. 


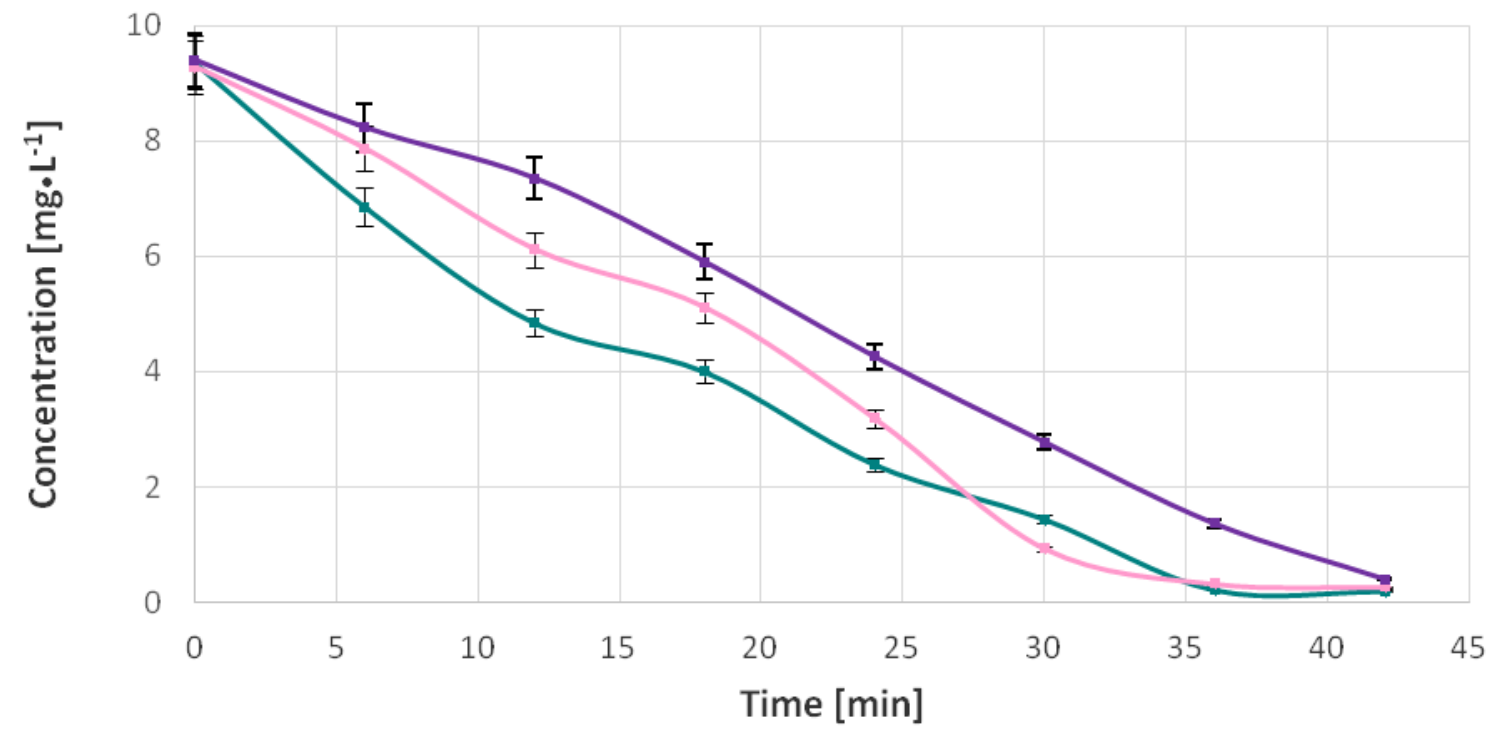

Fig. 2. Comparison of the effect of titanium oxides on $\mathrm{PBSA}$ degradation: $-\square-\mathrm{TiO}_{2} \mathrm{P} 25 ;-\square-\mathrm{TiO}_{2} \mathrm{PC} \mathrm{C}$; $;-\square-\mathrm{TiO}_{2}$ PC500

Source: Author's

The catalyst dose is of great importance in the PBSA photodegradation process. The heterogeneous photolysis reaction was performed using 1, 5, 10, 20 and $40 \mathrm{mg}$ of $\mathrm{TiO}_{2} \mathrm{P} 25$. It was found that with the increase of the $\mathrm{TiO}_{2}$ dose, the rate of PBSA degradation increases (Fig. 3.). After 15 minutes of reaction, in the mixture with the highest dose of $\mathrm{TiO}_{2}$, the filter concentration loss was found to be $85 \%$. However, in the mixture with $1 \mathrm{mg}$ of $\mathrm{TiO}_{2}$, this result was achieved not before 50 minutes of reaction. However, it should be noted that the use of a large amount of catalyst involves the need to carry out filtration of the system prior to performing the determination of PBSA concentration, because the catalyst suspension precludes measurement and can contaminate the apparatus.

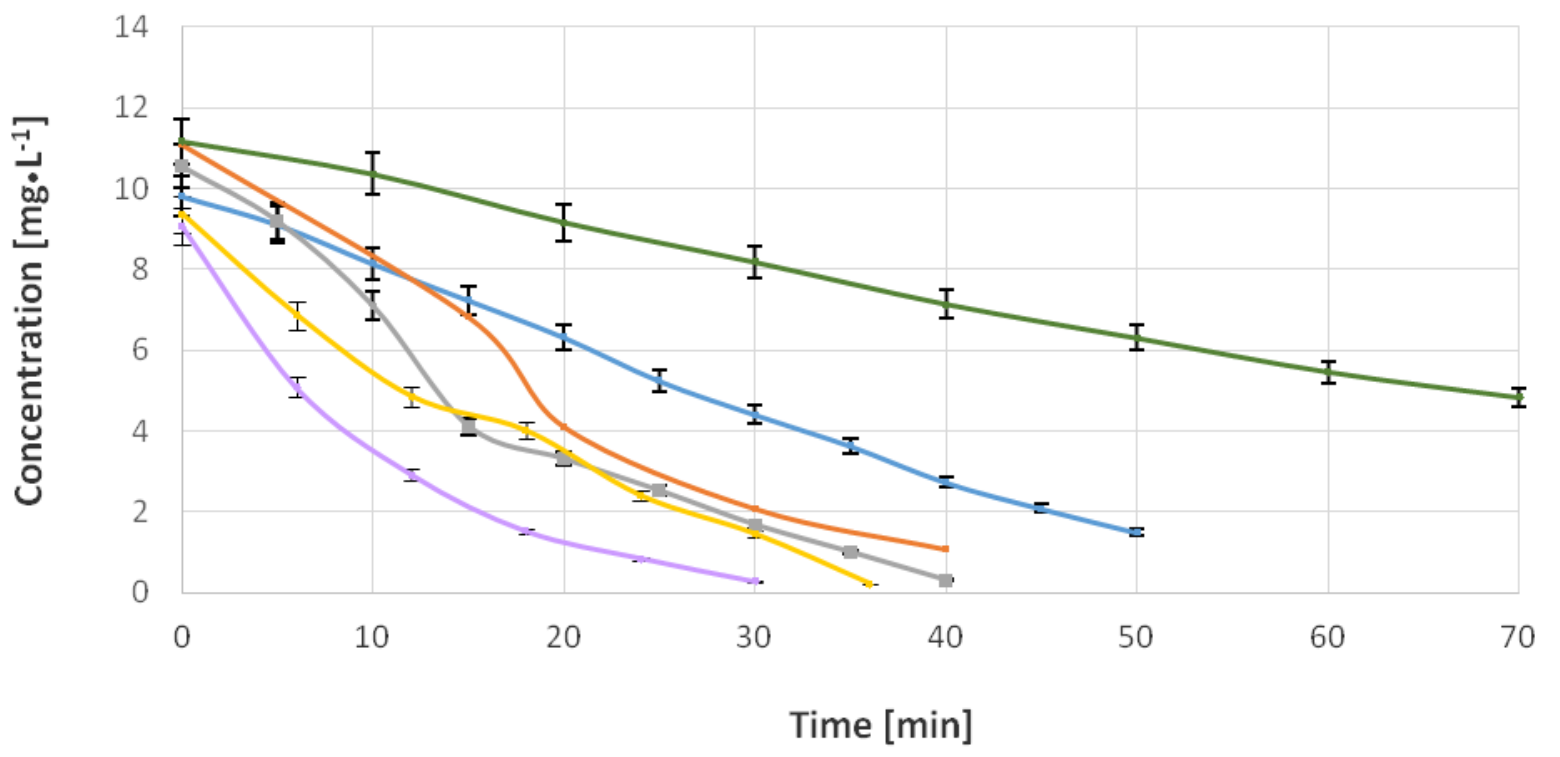

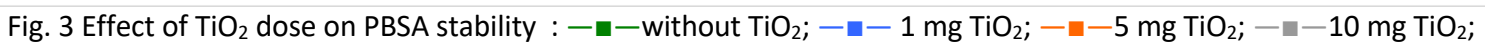
$-20 \mathrm{mg} \mathrm{TiO}{ }_{2} ;-\square-40 \mathrm{mg} \mathrm{TiO}{ }_{2}$ Source: Author's 
Another important parameter that should be taken into consideration during the heterogeneous photolysis of PBSA is $\mathrm{pH}$ of solution. The systems with addition of $1 \mathrm{mg} \mathrm{TiO}{ }_{2}$ adjusted to $\mathrm{pH} 3,5$ and 12 , respectively, and the system without addition of buffer $\mathrm{pH}=7$ were used in the studies. The effect of solution $\mathrm{pH}$ on photocatalytic degradation is a complex problem related to the ionization states of organic compounds, the catalyst surface charge as well as the formation rate of $\mathrm{HO} \bullet$ and other active radicals in the reaction solution [30, 31]. The $\mathrm{pH}$ of the solution also changes the energy level (2 energy levels) $\mathrm{TiO}_{2}$ [32]. According to our studies, PBSA photodegradation in the presence of $\mathrm{TiO}_{2}$ depends on $\mathrm{pH}$. It was observed that degree of degradation in acidic medium is considerably higher than at neutral pH (Fig. 4). According to Ji et al. [9], it can be caused by electrostatic attraction between $\mathrm{TiOH}_{2}{ }^{+}$and PBSA-H, which facilitates adsorption of PBSA on the surface of $\mathrm{TiO}_{2}$.

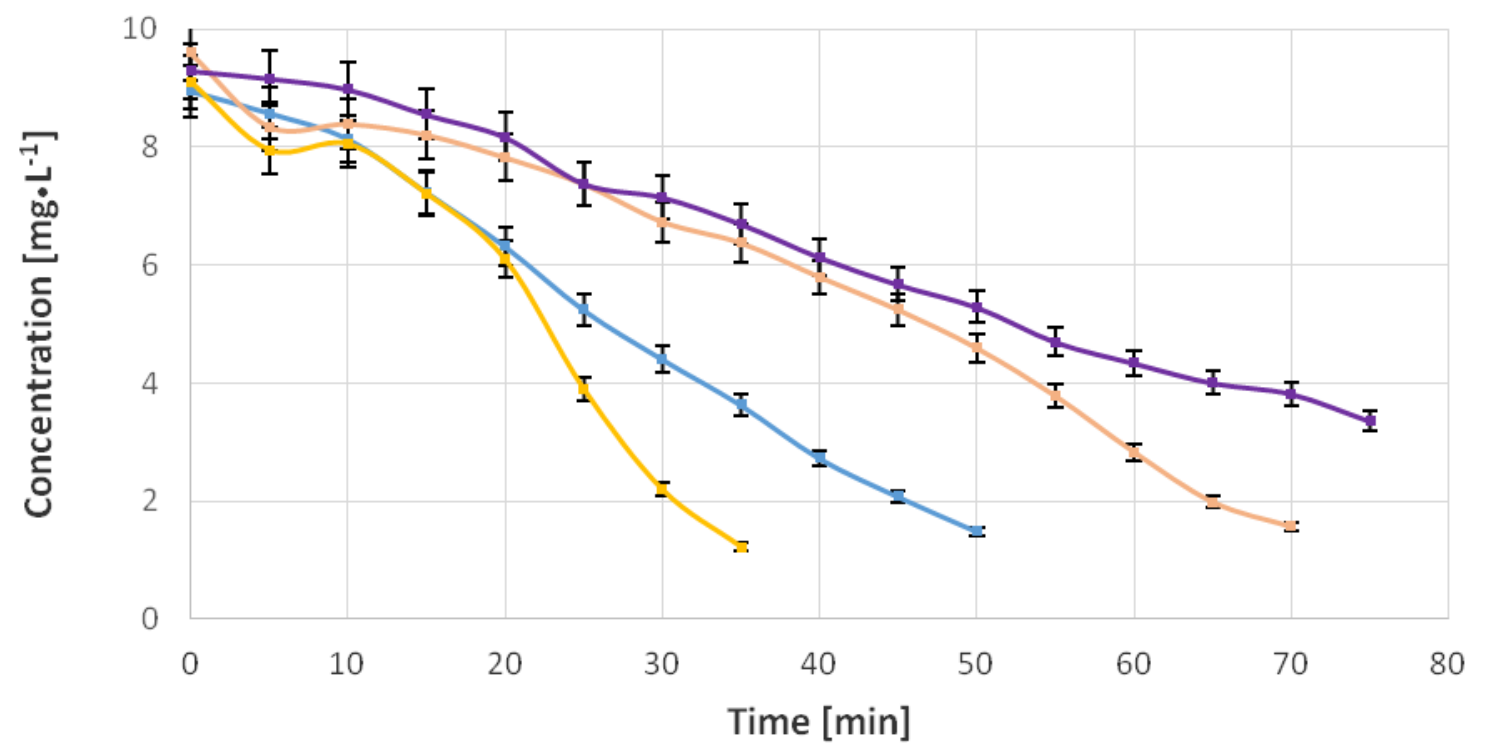

Fig. 4. Effect of $\mathrm{pH}$ on the rate of heterogeneous catalysis: : - - - without buffer; $-\square-$ buffer $\mathrm{pH}=3$; - - buffer $\mathrm{pH}=5$; - - buffer $\mathrm{pH}=12$

Source: Author's

The photodegradation process in an alkaline medium runs differently. In an alkaline medium $(\mathrm{pH} \geq 12)$, electrostatic repulsion between $\mathrm{TiO}^{-}$and $\mathrm{PBSA}-2 \mathrm{H}$ is much stronger than the effect of $\mathrm{HO} \bullet$ formation, which consequently slows degradation of the compound [9]. Similar results were obtained by Soto-Vazquez [33]. The results obtained indicate an important role of $\mathrm{TiO} 2$ in the photolysis process. Previous studies on PBSA photodegradation without $\mathrm{TiO} 2$ at different $\mathrm{pH}$ have shown that the protonated form of PBSA-2H was excited, moreover quantum efficiencies in the basic and acidic media were much higher than in neutral medium and this affects the increase in degradation rate [34]. Similar results were obtained by Tsoumachidou et al., who studied the effect of $\mathrm{pH}$ on the photocatalysis of another UV filter $p$-aminobenzoic acid (PABA). They found that the degradation proceeds faster in the acid medium, while in the alkaline medium the rate of photocatalysis decreases [35].

\section{Conclusion}

Photodegradation of water solution of 2-phenylbenzimidazole-5-sulfonic acid (PBSA) in the presence of a $\mathrm{TiO}_{2}$ catalyst suspension was carried out. Presence of $\mathrm{TiO}_{2}$ distinctly affects degradation of PBSA. The rate of degradation of the compound tested depends on catalyst dose and $\mathrm{pH}$ of the reaction medium. The study on the effect of $\mathrm{pH}$ on PBSA solution showed that the highest degradation occurred at $\mathrm{pH}=3$. However, in basic medium, the process proceeds slowly. Heterogeneous photocatalysis with participation of $\mathrm{TiO}_{2}$ is $\mathrm{Considered}$ to be one of the methods of advanced oxidation processes (AOP). The results obtained indicate that it can be used for degradation of organic pollutants, such as sunscreens. Due to its photochemical properties, $\mathrm{TiO}_{2} \mathrm{can}$ directly oxidize the adsorbed chemical substance or form an adsorbed hydroxyl radical HO. This, in turn, as a 
reactive oxidant, is capable of non-selective reaction with the most resistant organic substances polluting water.

\section{References}

[1] EPA, Contaminants of Emerging Concern including Pharmaceuticals and Personal Care Products, in, United States Environmental Protection Agency, (Acessed 26 April 2017).

[2] S.A. Snyder, P. Westerhoff, Y. Yoon, D.L. Sedlak, Pharmaceuticals, personal care products, and endocrine disruptors in water: implications for the water industry, Environ. Eng. Sci. 20 (2003) 449-469.

[3] D.L. Giokas, A. Salvador, A. Chisvert, UV filters: from sunscreens to human body and the environment, TrAC Trends Anal. Chem. 26 (2007) 360-374.

[4] M. Celeiro, F.V. Hackbarth, S.M.A. Guelli U. de Souza, M. Llompart, V.J.P. Vila, Assessment of advanced oxidation processes for the degradation of three UV filters from swimming pool water, J. Photochem. Photobiol. A: Chem. 351 (2018) 95-107.

[5] M.S. Díaz-Cruz, P. Gago-Ferrero, M. Llorca, D. Barceló, Analysis of UV filters in tap water and other clean waters in Spain, Anal. Bioanal. Chem. 402 (2012) 2325-2333.

[6] D.A. Lambropoulou, D.L. Giokas, V.A. Sakkas, T.A. Albanis, M.I. Karayannis, Gas chromatographic determination of 2-hydroxy-4-methoxybenzophenone and octyldimethyl-p-aminobenzoic acid sunscreen agents in swimming pool and bathing waters by solid-phase microextraction, J. Chromatogr. A. 967 (2002) 243253.

[7] M. Vila, J.P. Lamas, C. Garcia-Jares, T. Dagnac, M. Llompart, Ultrasound-assisted emulsification microextraction followed by gas chromatography-mass spectrometry and gas chromatography-tandem mass spectrometry for the analysis of UV filters in water, Microchem. J. 124 (2016) 530-539.

[8] S. Ramos, V. Homem, A. Alves, L. Santos, Advances in analytical methods and occurrence of organic UVfilters in the environment: a review, Sci. Total Environ. 526 (2015) 278-311.

[9] Y. Ji, L. Zhou, C. Ferronato, A. Salvador, X. Yang, J. Chovelon, Degradation of sun-screen agent 2phenylbenzimidazole-5-sulfonic acid by $\mathrm{TiO}_{2}$ photocatalysis:kinetics, photoproducts and comparison to structurally related compounds, Appl. Catal. B: Environ. 140-141 (2013) 457-467.

[10] R. Rodil, J.B. Quintana, P. López-Mahía, S. Muniategui-Lorenzo, D. Prada- Rodríguez, Multiclass determination of sunscreen chemicals in water samples by liquid chromatography-tandem mass spectrometry, Anal. Chem. 80 (2008) 1307-1315.

[11] W.H.M. Abdelraheem, X. He, X. Duan, D.D. Dionysiou, Degradation and mineralization of organic UV absorber compound 2-phenylbenzimidazole-5-sulfonic acid (PBSA) using UV-254nm/ $\mathrm{H}_{2} \mathrm{O}_{2}$, J Hazard Mater. 23 (282) $233-240$

[12] M. Schlumpf, P. Schmid, S. Durrer, M. Conscience, K. Maerkel, M. Henseler, M. Gruetter, I. Herzog, S. Reolon, R. Ceccatelli, Endocrine activity and developmental toxicity of cosmetic UV filters: an update, Toxicology. 205 (2004) 113-122.

[13] K.L. Kinnberg, G.I. Petersen, M. Albrektsen, M. Minghlani, S.M. Awad, B.F. Holbech, J.W. Green, P. Bjerregaard, H. Holbech, Endocrine-disrupting effect of the ultraviolet filter benzophenone-3 in zebrafish, Danio rerio, Environ. Toxicol. Chem. 34 (12) (2015) 2833-2840.

[14] L. Off. J. Eur. Union, Directive 2008/105/EC of the European Parliament and of the Council of 16 December 2008 on environmental quality standards in the field of water policy, as amended by Directive 2013/39/EU of the European Parliament and of the Council of 12 August 2013 amending Directives 2000/ 60/EC and 
2008/105/EC as regards priority substances in the field of water policy, in Off. J. Eur. Union, L 226/1., 2013., in, 2013.

[15] Y.S. Liu, G.G. Ying, A. Shareef, R.S. Kookana, Occurrence and removal of benzotriazoles and ultraviolet filters in a municipal wastewater treatment plant, Environ. Pollut. 165 (2012) 225-232.

[16] M.M. Tsui, H. Leung, P.K. Lam, M.B. Murphy, Seasonal occurrence, removal efficiencies and preliminary risk assessment of multiple classes of organic UV filters in wastewater treatment plants, Water Res. 53 (2014) 58-67.

[17] S. Ramos, V. Homem, A. Alves, L. Santos, A review of organic UV filters in wastewater treatment plants, Environ. Int. 86 (2016) 24-44.

[18] M.M. Tsui, H. Leung, T.C. Wai, N. Yamashita, S. Taniyasu, W. Liu, P.K. Lam, M.B. Murphy, Occurrence, distribution and ecological risk assessment of multiple classes of UV filters in surfach waters from different countries, Water Res. 67 (2014) 55-65.

[19] V.A. Sakkas, D.L. Giokas, D.A. Lambropoulou, T.A. Albanis, Aqueous photolysis of the sunscreen agent octyl-dimethyl-p-aminobenzoic acid: formation of disinfection byproducts in chlorinated swimming pool water, J. Chromatogr. A. 1016 (2003) 211-222.

[20] N. Negreira, P. Canosa, I. Rodriguez, M. Ramil, E. Rubi, R. Cela, Study of some UV filters stability in chlorinated water and identification of halogenated by-products by gas chromatography- mass spectrometry, J. Chromatogr. A. 1178(1) (2008) 206-214.

[21] A. Gackowska, W. Studziński, J. Gaca, Effect of sodium hypochlorite on conversions of octyl-dimethyl- para -aminobenzoic acid, Desalin. Water Treat., 57(3) (2016) 1429-1435.

[22] T. Heberer, K. Reddersen, A. Mechlinski., From municipal sewage to drinking water: fate and removal of pharmaceutical residues in the aquatic environment in urban areas, Water Sci Technol. 46 (2002) 81-88.

[23] Y. Liu, X. He, X. Duan, Y. Fu, D.D. Dionysiou, Photochemical degradation of oxytetracycline: influence of $\mathrm{pH}$ and role of carbonate radical, Chem. Eng. J. 276 (2015) 113-121.

[24] S. Giannakis, F.A.G. Vives, D. Grandjean, A. Magnet, L.F. De Alencastro, C. Pulgarin, Effect of Advanced Oxidation Processes on the micropollutants and the effluent organic matter contained in municipal wastewater previously treated by three different secondary methods, Water Res. 84 (2015) 295-306.

[25] N. De la Cruz, L. Esquius, D. Grandjean, A. Magnet, A. Tungler, L.F. De Alencastro, C. Pulgarin, Degradation of emergent contaminants by UV, UV/ $\mathrm{H}_{2} \mathrm{O}_{2}$ and neutral photo-Fenton at pilot scale in a domestic wastewater treatment plant, Water Res. 47 (2013) 5836-5845.

[26] C.H. Jo, A.M. Dietrich, J.M. Tanko, Simultaneous degradation of disinfectionbyproducts and earthy-musty odorants by the UV/ $\mathrm{H}_{2} \mathrm{O}_{2}$ advanced oxidationprocess, Water Res. 45 (2011) 2507-2516.

[27] T.E. Doll, F.H. Frimmel, Removal of selected persistent organic pollutants by heterogeneous photocatalysis in water, Catal. Today. 101 (2005) 195-202.

[28] S.H.S. Chan, T. Yeong Wu, J.C. Juan, C.Y. Teh, Recent developments of metal oxide semiconductors as photocatalysts in advanced oxidation processes (AOPs) for treatment of dye waste-water, J. Chem. Technol. Biotechnol. 86 (2011) 1130-1158.

[29] E. Voigtman, Limits of Detection in Chemical Analysis, Hoboken, NJ : Wiley (2017)

[30] M. Nan Chong, B. Jin, C.W.K. Chow, C. Saint, Recent developments in photocatalytic water treatment technology: a review, Water Research 44 (2010) 2997-3027. 
[31] E. Hapeshi, A. Achilleos, M.I. Vasquez, C. Michael, N.P. Xekoukoulotakis, D. Mantzavinos, D. Kassinos, Drugs degrading photocatalytically: Kinetics and mechanisms of ofloxacin and atenolol removal on titania suspensions, Water Research 44 (2010) 1737-1746.

[32] H. Park, Y. Park, W. Kim, W. Choi, Surface modification of $\mathrm{TiO}_{2}$ photocatalyst for environmental applications,Journal of Photochemistry and Photobiology C: Photochemistry Reviews 15 (2013) 1-20.

[33] L. Soto-Vázquez, M. Cotto, J. Ducongé, C. Morant, F. Márquez, Synthesis and photocatalytic activity of TiO2 nanowires in the degradation of p-aminobenzoic acid: A comparative study with a commercial catalyst, $\underline{J}$ Environ Manage. 167 (2016) 23-8.

[34] W. Studziński, A. Karczmarek, Effect of various agents on stability of 2-phenylbenzimidazole-5-sulfonic acid, Acta Innovations 25 (2017) 5-21.

[35] S. Tsoumachidou, T. Velegraki, I. Poulios, TiO2 photocatalytic degradation of UV filter para-aminobenzoic acid under artificial and solar illumination, Journal of technology and biotechnology 91(2016) 1773-1781. 